[This is an Accepted Manuscript of an article published in Ethical Perspectives 22/1 (2015), 6998. The final publication is available via http://www.ethical-

perspectives.be/page.php?FILE=ep_detail\&ID=205\&TID=1849. Please cite the published version only.]

\title{
Wittgenstein, Meta-Ethics and the Subject Matter of Moral Philosophy
}

\author{
Benjamin De Mesel \\ KU Leuven, Belgium
}

\begin{abstract}
Several authors claim that, according to Wittgenstein, ethics has no particular subject matter and that, consequently, there is and can be no such thing as meta-ethics. These authors argue that, for Wittgenstein, a sentence's belonging to ethics is a classification by use rather than by subject matter and that ethics is a pervasive dimension of life rather than a distinguishable region or strand of it. In this article, I will critically examine the reasons and arguments given for these claims. In my view, a Wittgensteinian perspective does not exclude the possibilities of doing meta-ethics and of there being a particular subject matter of moral philosophy. These alleged impossibilities are not the distinguishing marks of Wittgensteinian moral philosophy. What distinguishes Wittgensteinian moral philosophy from traditional moral philosophy is, rather, its emphasis on alternative ways of thinking about the subject matter of moral philosophy.
\end{abstract}

KEYWORDS. Ludwig Wittgenstein, ethics, meta-ethics, moral philosophy, subject matter

\section{INTRODUCTION}

In 2002, a special issue of the journal Philosophical Papers, "Ethics in the Light of Wittgenstein", was devoted to the relation between Wittgenstein's philosophy and ethics. ${ }^{1}$ Several articles in that issue, as well as some others, contain a set of closely interconnected claims that I will critically examine here. First, several authors claim that, according to Wittgenstein, ethics has no particular subject matter (section 2). Second, they argue that, because ethics has no particular subject matter, there is and can be no such thing as meta-ethics (section three). Third, according to them, a sentence's belonging to ethics is a classification by use rather than by subject matter (section four). Fourth, they aver that, for Wittgenstein, ethics is a pervasive dimension of life rather than a distinguishable region or strand of it (section five). In my view, however, Wittgenstein does not exclude the possibilities of doing meta-ethics and of there being a particular subject matter of moral philosophy. What distinguishes Wittgensteinian moral philosophy from traditional moral philosophy is, rather, its emphasis on alternative ways of thinking about the subject matter of moral philosophy (section six).

Before starting the discussion of these claims, I would like to emphasize two things. First, the authors I discuss hold similar views, but these views are not exactly the same. In what follows, I will 
[This is an Accepted Manuscript of an article published in Ethical Perspectives 22/1 (2015), 6998. The final publication is available via http://www.ethical-

perspectives.be/page.php?FILE=ep_detail\&ID=205\&TID=1849. Please cite the published version only.]

focus on similarities rather than differences, and I may not be able to do full justice to the specific contexts in which each author has developed the views under scrutiny. The authors will be treated as exemplifying a certain trend or tendency, and it is the latter that I will criticize. Put otherwise, the authors go their own way, but in the same direction, and I will try to show what is problematic about that direction. Second, the focus will be on views I disagree with. The fact that the balance between disagreement and agreement with several authors tilts, in this article, towards disagreement, should not be taken to reflect my overall evaluation of their contributions to Wittgensteinian moral philosophy, as I will make clear in the conclusion.

\section{2. "ETHiCS has NO PARTICULAR SUBJECT MATTER"}

Cora Diamond writes that, on a Wittgensteinian conception of ethics, "ethics has no particular subject matter" $(2000,153)$. Similar statements can be found in other work of hers and in articles by Duncan Richter (1996, 252), Lars Hertzberg (2002, 255), Stephen Mulhall (2002, 293) and James Conant (2002, 87). Why do they think that, for Wittgenstein, ethics has no particular subject matter?

In "Wittgenstein, Mathematics, and Ethics" (1996), Diamond criticizes Sabina Lovibond's treatment of ethics in Realism and Imagination in Ethics (1983). Lovibond, she says, assumes that what makes ethical sentences ethical is the occurrence of moral predicates. We tend to have the idea of something like a "moral vocabulary" (Diamond 1996, 252), a limited set of moral words. We tend to think that, if a word from this set occurs in a sentence, then that sentence is an ethical sentence, because the word denotes or refers to a moral property and moral properties are the subject matter of ethics. According to Diamond, this idea "of sentences as about moral subject matter through the presence in them of moral words" $(1996,252)$ is badly mistaken, because those who hold it fail to take into account the Wittgensteinian insight that what a sentence or word means is determined by its use. Hence, the occurrence of a certain word in a sentence does not fix its status as an ethical sentence: "[...] a sentence's belonging to ethics is a classification by use" $(1996,237)$. Diamond then goes on to show that sentences without any typically moral words ("good", "right”, "bad", “wrong”, “duty”, “obligation”, "virtue”) can be ethical sentences. She convincingly argues that, in certain contexts, the insertion of these words may even distort the ethical meaning of a sentence.

First of all, let me say that I agree with Diamond's insistence on the relative irrelevance of typically "moral" vocabulary. The occurrence of this or that word does not make a sentence into an ethical sentence, nor does the absence of typically moral words or predicates preclude a sentence from being an ethical sentence. Whether a sentence or a word is ethical or not is indeed determined by its use. 
[This is an Accepted Manuscript of an article published in Ethical Perspectives 22/1 (2015), 6998. The final publication is available via http://www.ethical-

perspectives.be/page.php?FILE=ep_detail\&ID=205\&TID=1849. Please cite the published version only.]

Diamond refers in this context to Simone Weil, in whose work the word "chance" is an ethical word, and shows how the sentence "It is only through chance that I was born" can be an ethical sentence (1996, 247). The upshot of Diamond's argument is that there is no limited, clearly determinable set of moral words. We cannot make a list and say: these are the moral words, and there are no others. In that respect, Diamond is right to emphasize that moral philosophy has all too often focused on certain words. That there is no limited set of moral words does not mean, however, that there is no moral vocabulary. Diamond writes:

There is not, on this view [the Tractatus view of ethics], a "moral vocabulary", a vocabulary through which we mean moral things. If one wanted to give sense to "moral vocabulary" one might mean: vocabulary we use in saying things that might have application in moral life, but that excludes no words. Since the Tractatus might have such use (and was intended to), "variable", "Frege" and "Theory of Types" belong, in this sense, to "moral vocabulary" (1996, 252-253).

Diamond discusses here the Tractatus view of ethics, but she suggests that the later Wittgenstein did not think that there is a moral vocabulary either. In discussing Lovibond's treatment of the later Wittgenstein, Diamond criticizes "the very idea of "the moral vocabulary" (1996, 251). Why does Diamond suggest that, for Wittgenstein, there is no moral vocabulary? She may have reasoned as follows: if many seemingly non-moral words may be used in such a way as to acquire a moral sense, a moral vocabulary (if we allow for the idea at all) would be a long list of all kinds of words "that might have application in moral life", including, for example, "variable". If indeed a moral vocabulary is a list of words moral philosophy should focus on and if this list would be very long, then moral philosophy would lose all focus: it would then have to study the use of almost every word, including "variable", and the very term "moral philosophy" would become empty. A list of moral words would hardly be distinguishable from a list of all the words in a dictionary.

This argument is problematic. It seems as if Diamond does not take sufficiently into account here the Wittgensteinian insight she has been emphasizing: that meaning is use. If what makes "chance" a moral word in some cases is its specific use in these cases, then a moral vocabulary will include the word "chance" with a specification of use: in such and such cases, when used so and so, the word "chance" is a moral word. Why would it be impossible or undesirable to speak of a vocabulary when such specifications are needed? If it would, then no specific vocabulary, be it an ethical one or not, would be possible at all, because there is no reason to assume that Wittgenstein restricted his idea that meaning is use to ethical sentences (on meaning and use, see section 4).

Throughout her article, Diamond contrasts ethical sentences with sentences about botany. If we take Diamond's reference to "meaning is use" seriously, we should say that sentences about botany are 
[This is an Accepted Manuscript of an article published in Ethical Perspectives 22/1 (2015), 6998. The final publication is available via http://www.ethical-

perspectives.be/page.php?FILE=ep_detail\&ID=205\&TID=1849. Please cite the published version only.]

about botany in virtue of their use, and there seems to be nothing wrong with that: the occurrence of typical plant-words does not seem to be a necessary condition for a sentence to be about plants, and plant-words may occur in a sentence without it necessarily being about plants. Can we make a limited list of plant-words, saying that these and only these are the words the occurrence of which makes a sentence into a botanical one? We probably cannot. Does this mean that there is no botanical vocabulary? It does not. What it means is that, on a Wittgensteinian view, any specific vocabulary, be it an ethical or a botanical one, will only count as an ethical or botanical vocabulary if it specifies that certain words are only ethical or botanical when used in such and such ways (which is, after all, not a strange idea: a dictionary contains many such specifications of use). The moral vocabulary will include "chance" and "variable" in their moral uses. These moral uses can be specified by giving examples: when used thusand-so, these words are moral words. Hertzberg, echoing Diamond, writes that "explicit moral locutions are neither necessary nor sufficient for a conversation to be understood as expressive of moral concerns" (2002, 256). This way of putting things is confused: there are no "moral locutions" irrespective of their being used as such: if the locutions are moral (which does not mean, according to Diamond and Hertzberg, "if they contain typically moral words", but "if they are used so as to be moral"), then they are (almost trivially, I would say) expressive of moral concerns.

The moral vocabulary is not, as Diamond claims, the whole set of words "that might have application in moral life" (my italics), a set that may be thought to exclude no words, but the set of words that have such an application, and the application of which is being specified. Hence, it excludes a lot, namely all non-moral words (that is, all words in non-moral uses). What Diamond has shown is that it includes more than is commonly thought, that moral word-use is richer, more varied than we tend to think, that the number of moral words may be indefinite because the number of possible moral uses may be indefinite and that moral words may not be sharply distinguishable from non-moral words. Moreover, moral vocabulary may well be more "open" or "flexible" than other kinds of vocabulary, consisting of a lot of words which also occur in other vocabularies (such as "chance"), while botanical vocabulary is more closed ("chance," for example, is not likely to be used in such a way as to acquire a botanical sense). None of these insights, however, leads to the conclusion that there is no moral vocabulary.

Why is the impossibility of a moral vocabulary (on Diamond's understanding of "vocabulary" as a limited list of words without any specification as to their use) important to those who claim that ethics has no particular subject matter? It is often thought that, if ethics has a subject matter, this subject matter consists of moral properties (such as, for example, rightness and wrongness). Moral properties are referred to by a moral vocabulary. If there is no such vocabulary, there are no such properties, and hence no subject matter. This line of reasoning is flawed by Wittgensteinian standards. The occurrence of words such as "right" and "wrong", that is, the surface grammar of a sentence, may be misleading 
[This is an Accepted Manuscript of an article published in Ethical Perspectives 22/1 (2015), 6998. The final publication is available via http://www.ethical-

perspectives.be/page.php?FILE=ep_detail\&ID=205\&TID=1849. Please cite the published version only.]

and does not guarantee that reference is made to moral properties. Similarly, nothing precludes a sentence like "It is only through chance that I was born", in its moral use, from referring to a moral property such as goodness. Whether there is a moral vocabulary (again, on Diamond's understanding of it) or not, and which words it includes, does not necessarily inform us about the existence or nonexistence of moral properties. $^{2}$

It may be said that what Diamond wants to emphasize is not so much that, according to Wittgenstein, there is no moral vocabulary, but that there is no limit to it $(1996,248)$. Mulhall mentions Diamond's "emphasis upon the absence of pre-given limits to what might count as an ethical use of language" $(2002,310)$. Similarly, Richter writes that "there is no limit that can be set to what language could be moral" (1996, 254). I agree with this, but not with what these authors take to follow from it. They seem to say: because there is no limit to what may count as moral language, there is, for Wittgenstein, "no special ethical arena" (Richter 1996, 254), "no special area of thought or life or language about which we can do philosophy of a peculiarly moral kind” (Richter 1996, 253). "Ethics', in Wittgenstein's vocabulary" does not name "an independent subject matter or separable area of philosophy" (Conant 2002, 87), "a branch of philosophy with its own proprietary subject matter" (Conant 2002, 90). According to Wittgenstein, morality is not "an area of its own" (Hertzberg 2002, 268), not a "separable domain or concern of human existence as such" (Mulhall 2002, 304), not a "region or strand" of life (Mulhall 2002, 305), and philosophers have been "plowing a non-existent field" (Hertzberg 2002, 270). I think that two mistakes, both already hinted at, are involved in concluding this. First, these authors seem to presuppose that characteristics of moral language (as they understand it) carry over to its subject matter (M1). Because the language is varied, the subject matter is. Because almost every sentence can be moral, if it is used in a certain way, moral sentences can be about almost anything. Because there are indefinitely many ways of using moral language, there are indefinitely many moral properties. If there are indefinitely many moral properties and if moral sentences can be about almost anything, almost anything counts as the subject matter of moral philosophy. Hence, the whole idea of a subject matter (like the idea of a moral language or a moral vocabulary) becomes empty. The relation between moral language and its subject matter assumed here is a pictorial relation in which language stands in a one-to-one relation to what it is about, to its subject matter. It does not need to be argued that the later Wittgenstein has shown this model, often associated with the Tractatus, to be inaccurate. An indefinite set of moral words can go together with a definite, even a very limited set of moral properties and with a specifiable subject matter. ${ }^{3}$

One could argue that Diamond, Richter, Hertzberg and Mulhall do not presuppose at all that characteristics of moral language carry over to its subject matter. In doing that, one would have to show why they all insist both on the variety of moral language and on there being no subject matter of moral 
[This is an Accepted Manuscript of an article published in Ethical Perspectives 22/1 (2015), 6998. The final publication is available via http://www.ethical-

perspectives.be/page.php?FILE=ep_detail\&ID=205\&TID=1849. Please cite the published version only.]

philosophy, if this variety has no obvious consequences for the subject matter or vice versa. But even if they do not commit the first mistake (M1), I think they are subject to a second one (M2). Suppose that it can indeed be shown that the moral subject matter, the ethical "arena", is overwhelmingly varied and far more extensive than most philosophers have thought. Why and how would that amount to there not being a moral arena? The mistake here runs parallel to what I said about moral vocabulary: just as the variety of moral word-use in no way indicates that there is no moral vocabulary, the variety of the moral arena in no way indicates that there is no moral subject matter, it only points at the complexity of that subject matter. So while our authors rightfully problematize the ideas of a moral vocabulary and a moral subject matter, I do not think that a Wittgensteinian perspective should lead them to deny that there is a moral vocabulary and a moral subject matter.

I conclude that, although the authors mentioned above succeed in showing the variety of moral word-use, they fail to indicate why this variety would lead to the absence of a particular subject matter of moral philosophy. Moreover, although they characterize their insights as Wittgensteinian, it can be doubted whether Wittgenstein indeed thought that there is no such subject matter. On the contrary, Wittgenstein seems to have thought just the opposite. In "A Lecture on Ethics", he writes:

\footnotetext{
My subject, as you know, is ethics and I will adopt the explanation of that term which Prof. Moore has given in his book Principia Ethica. He says: "Ethics is the general inquiry into what is good." Now I am going to use the term "ethics" in a slightly wider sense [...] And to make you see as clearly as possible what I take to be the subject matter of ethics I will put before you a number of more or less synonymous expressions each of which could be substituted for the above definition [...] if you look through the row of synonyms I will put before you, you will, I hope, be able to see the characteristic features they all have in common and these are the characteristic features of ethics. $(2014,43)$
}

Wittgenstein explicitly refers to the subject matter of ethics in this passage. ${ }^{4}$ This subject matter can be roughly specified: ethics is about what is good. The idea of a subject matter can go together with Diamond's observation that one can talk about what is good in indefinitely many ways, but it straightforwardly contradicts the statement that ethics has, according to Wittgenstein, no particular subject matter. At this point, I see only one possible line of defense. The quoted passage occurs in "A Lecture on Ethics", commonly taken to be written by the early Wittgenstein. ${ }^{5}$ The later Wittgenstein changed his mind, and in saying that, according to Wittgenstein, ethics has no particular subject matter, reference was made to the later Wittgenstein. One would not expect Diamond to take this road: she has always emphasized the continuity between the early and the later Wittgenstein. A similar emphasis on the continuity between early and later Wittgenstein can be found in the works of Conant, Mulhall (2002, 304) and Richter, who explicitly states that "at least in terms of his attitude towards ethics, 
[This is an Accepted Manuscript of an article published in Ethical Perspectives 22/1 (2015), 6998. The final publication is available via http://www.ethical-

perspectives.be/page.php?FILE=ep_detail\&ID=205\&TID=1849. Please cite the published version only.]

Wittgenstein's thinking changed little during his career" $(1996,243)$. If they are right about the continuity, it seems false to say that, for Wittgenstein, ethics has no particular subject matter.

\section{3. "There Is AND CAN Be No Such Thing as Meta-ETHics"}

In the opening lines of his article "Ethics in the Light of Wittgenstein" (2002), Mulhall remarks that

[...] those of his [Wittgenstein's] followers who have wanted to explore and develop a distinctively Wittgensteinian approach to ethics have tended to do so by applying what they conceive to be his general methodological principles to this particular subject matter. The basic assumption here is that moral philosophy, like philosophy of language and philosophy of mind, is one of the many distinctive branches or sectors into which philosophy as a whole can be divided [...] $(2002,293)$

In the rest of his article, Mulhall attacks this "basic assumption" and defends the claim that, unlike philosophy of language and philosophy of mind, moral philosophy has no particular subject matter. We tend to think that it has, because we think "that we can demarcate the domain of moral philosophy by reference to a characteristic list or system of distinctively moral concepts" $(2002,304)$. There is no such list. Therefore, the domain cannot be demarcated. Therefore, there is no particular subject matter.

What exactly is the difference between moral concepts and distinctively moral concepts? In order to make such a difference, one would have to assume that there are moral concepts that are not distinctively moral. One could think here, I suppose, of goodness, and say that goodness is a moral concept, although not distinctively moral, because we talk, for example, about good knives. Again, what is overlooked here is that meaning is use: in talking about a good knife, one could say that we use the concept of goodness, but goodness is not a moral concept here, because it is not used as such. Hence, every moral concept is a distinctively moral concept. Mulhall, I take it, may also grant this, but emphasize that a list of such concepts will not be limited. Therefore, it will not help us to demarcate the domain of moral philosophy $(2002,303)$. The alleged need for demarcation explains Mulhall's use of "distinctive(ly)". It also explains why Richter writes that, for Wittgenstein, there is no special ethical arena about which we can do philosophy of a peculiarly moral kind and why both Diamond and Mulhall do not just say that ethics has no subject matter, but that it has no particular subject matter. In the same vein, Conant claims that, according to Wittgenstein, there is no independent or proprietary subject matter and that moral philosophy is not a separable area. The reasoning here seems to run parallel to what made the idea of a moral vocabulary unattractive to these authors: if we cannot demarcate the domain of moral philosophy, then moral philosophy can be about almost anything, and almost anything 
[This is an Accepted Manuscript of an article published in Ethical Perspectives 22/1 (2015), 6998. The final publication is available via http://www.ethical-

perspectives.be/page.php?FILE=ep_detail\&ID=205\&TID=1849. Please cite the published version only.]

would count as the subject matter of moral philosophy. One could say that there is a subject matter, but it would include almost anything, which makes it an almost empty thing to say. I agree with the conclusion that, if moral philosophy can be about almost anything, the idea of a subject matter becomes empty. I disagree, however, both with the thought that moral philosophy can be about almost anything (to which I will come back in the following sections) and with the thought that demarcation is needed for there to be a ("particular" or "special") subject matter.

In order to clarify the latter point, I would like to have a closer look at Mulhall's contrast between moral philosophy, on the one hand, and philosophy of language and philosophy of mind on the other. He refers to "the incoherence of the idea that moral philosophy is a separable branch or sector of philosophy more generally (on the model of philosophy of language or philosophy of mind)" (2002, 303-304). Mulhall sees a disanalogy here: while philosophy of language and philosophy of mind are "distinctive branches or sectors into which philosophy as a whole can be divided", moral philosophy is not. The use of "distinctive", "separable" and "divided" testifies of a need for demarcation and illustrates the link between subject matter and demarcation in Mulhall's article. "Demarcation", "division" and "distinction" can be understood in two ways here. Maybe Mulhall is asking for sharp distinctions and boundaries, that is, for the one and only demarcation of the one branch from the other, for closed and finite lists of words or concepts, preferably with no overlap, that would clearly distinguish one branch of philosophy from another. I do not see how such a list could be produced for philosophy of language, philosophy of mind or moral philosophy. One could, rightly I think, say that philosophy of language is about language and philosophy of mind is about the mind, but there is no disanalogy here with Wittgenstein's / Moore's saying that moral philosophy is the general inquiry into what is good. Just as it is not clear what counts as language and what not, and just as nobody knows what exactly the mind is, moral philosophers are still unclear about what counts as good, about what 'the good' is, about the meaning of 'good'. Moreover, there is considerable overlap between the domains: language can be moral, and moral language belongs both to the subject matter of philosophy of language and to the subject matter of moral philosophy. Because there are no sharp distinctions and boundaries here, we may take Mulhall not to refer to finite or closed lists of concepts or words when he uses "demarcate". This would be in line with Wittgenstein's pointing out that the absence of sharp boundaries, or the boundaries' having blurred edges in no way indicates that there are no boundaries (Wittgenstein 2009: $\S 71$ and § 77). Mulhall may not be looking for the demarcation, but asks for $a$ demarcation. Several demarcations of the same branch are possible and overlap between branches is allowed for. If this is the case, it becomes unclear why Mulhall asks for distinctively moral concepts, a separable branch of philosophy and a particular subject matter. What do these words add here? Can a particular subject matter of philosophy of language or mind be demarcated by pointing at distinctive concepts? Are these 
[This is an Accepted Manuscript of an article published in Ethical Perspectives 22/1 (2015), 6998. The final publication is available via http://www.ethical-

perspectives.be/page.php?FILE=ep_detail\&ID=205\&TID=1849. Please cite the published version only.]

separable branches of philosophy? This can be doubted, but nevertheless, philosophy of mind and language are uncontroversially taken to have a subject matter (at least by Mulhall himself). These subject matters, language and mind, have been demarcated in various ways and can be demarcated in indefinitely many ways. The same holds for the subject matter of moral philosophy, a demarcation of which is certainly possible, as the tradition of moral philosophy and Wittgenstein's/Moore's "what is good" show. In short: if a sharp demarcation is needed, none can be given for philosophy of mind, philosophy of language or moral philosophy. If a blurred demarcation is enough, many demarcations can be given for all three subjects. When it comes to demarcation, they all seem to be in very much the same boat.

Even if it is not wholly clear what kind of demarcation Mulhall is asking for, he allows for the possibility of at least some kind of demarcation, but he has two problems with it. First, he writes:

For how might one demarcate this separate domain of philosophy if not by means of some general characterization of moral reflection and action, conceived of as a conceptually distinct branch or sector of human existence? But any such characterization will, if the above argument is correct, amount not to a description but to a deployment of the concept supposedly under analysis. $(2002,304)$

We can demarcate the subject matter of moral philosophy after all, but such a demarcation will involve the "deployment of the concept supposedly under analysis". Apparently, it is a problem, threatening the usefulness of demarcation, if you demarcate a domain by deploying concepts under analysis in that domain. Here again, however, there is an analogy rather than a disanalogy of moral philosophy with philosophy of language and mind. Will not any adequate demarcation of philosophy of language or philosophy of mind refer to language or mind, that is, to concepts under analysis in these domains? If such demarcations are problematic, then Mulhall's claim that these domains can be demarcated stands in need of explanation: how exactly can this be done, if not by referring to language or mind?

Mulhall's second problem is that "There is no way of characterizing the subject-matter of moral philosophy that will not itself give expression to one's own ethical interests and concerns" $(2002,303)$. He may be right, but I can only repeat here that neither the first nor the second of Mulhall's problems amounts to the impossibility of there being a subject matter of moral philosophy. Mulhall himself, however, takes his demarcation problems as support for the conclusion "that there is and can be no such thing as meta-ethics" (2002, 303; see also Diamond 2000, 162). Because the subject matter of moral philosophy cannot be demarcated, at least not without deploying concepts under analysis in moral philosophy and without giving expression to one's own ethical interests, we have to acknowledge "the impossibility of moral philosophy as meta-ethics" $(2002,303)$. This is a striking claim: if meta-ethics 
[This is an Accepted Manuscript of an article published in Ethical Perspectives 22/1 (2015), 6998. The final publication is available via http://www.ethical-

perspectives.be/page.php?FILE=ep_detail\&ID=205\&TID=1849. Please cite the published version only.]

were impossible, then what have meta-ethicists been doing? And why do they think that meta-ethics is possible after all?

It is crucial, in this respect, to investigate Mulhall's conception of meta-ethics. First, Mulhall takes the possibility of meta-ethics to depend on the possibility of demarcating the subject matter of moral philosophy. As we have seen, this demarcation problem seems to be no problem at all (at least if, with Mulhall, one refuses to regard it as a problem for philosophy of language and philosophy of mind), regardless of one's taking the need for demarcation to be a need for sharp distinctions or not. Second, the possibility of meta-ethics depends on the possibility of yet another distinction: Mulhall criticizes Paul Johnston's assumption, in his Wittgenstein and Moral Philosophy (1989), "that a sharp distinction can be drawn between first-order ethics (advocacy) and meta-ethics (grammatical reminders about the logic of moral concepts)" (2002, 299). According to Mulhall, such a sharp distinction cannot be drawn, because grammatical reminders about the logic of moral concepts will always be expressive of one's ethical interests and concerns. If one demands of meta-ethics that it be normatively neutral, there can be no meta-ethics. If meta-ethics should be impersonal, if it should not involve any personal ethical commitments, there can be no meta-ethics. As Mulhall writes, "there simply is no space for the straightforward assumption of impersonal linguistic authority" (2002, 319). I agree with him here, but my question is: who would think that the sharp distinction Mulhall takes to be impossible can be drawn? Who would think that meta-ethics is normatively neutral and impersonal, not in any way expressive of the meta-ethicist's concerns? Mulhall mentions Stevenson, and refers to "the meta-ethical enterprise so characteristic of analytic moral philosophy in the first half of the twentieth century (and beyond)" (2002, 303). I do not deny that Stevenson and some others (Ayer, for example) may have thought the distinction to be sharp. But, just as there are nowadays not many moral philosophers who would say that the subject matter of ethics can be demarcated in a sharp way from the subject matter of other branches of philosophy, I am quite sure that most contemporary meta-ethicists would object to the idea that there is a sharp distinction between normative ethics and meta-ethics. Hence, there is no reason to suppose that meta-ethics, regardless of how one understands it (this may be what "there can be no meta-ethics" adds to "there is no meta-ethics"), is impossible without normative neutrality. That point is often explicitly emphasized by contemporary meta-ethicists. In the Stanford Encyclopedia of Philosophy (2012), we read:

In fact, metaethics has seemed to many to offer a crucial neutral background against which competing moral views need to be seen if they are to be assessed properly. Some metaethicists early in the twentieth century went so far as to hold that their own work made no substantive moral assumptions at all and had no practical implications. Whether any view that is recognizably still a view about the nature and status of ethics could manage this is dubious. (Sayre-McCord 2012) 
[This is an Accepted Manuscript of an article published in Ethical Perspectives 22/1 (2015), 6998. The final publication is available via http://www.ethical-

perspectives.be/page.php?FILE=ep_detail\&ID=205\&TID=1849. Please cite the published version only.]

In short, then, Mulhall's reasons for the claims that there is no particular subject matter of moral philosophy and that there can be no meta-ethics do not convince me, and I doubt whether they would convince many meta-ethicists. He puts much emphasis on demarcation, but problems with demarcation pass the question by. If I want to know whether philosophy of language has a subject matter and what that subject matter is, do I have to be able to demarcate "language"? Can't I do linguistics without knowing where the limits of language lie? Biology without knowing where the boundaries of life are? Do I have to know where the boundaries of a country are before I am able to go there and describe, investigate, know and understand what is in it? If I want to go there and talk about it, what is needed is not demarcation but, for example, names, descriptions, illustrations, characterizations. ${ }^{6}$ (Mulhall uses "characterization" to be sure, but he tends to use "characterization" interchangeably with "demarcation", thus reducing to demarcation the many ways in which a domain can be characterized.) Again, Mulhall is right, and has Wittgenstein on his side, when he problematizes distinctions between moral and nonmoral, between meta-ethics and normative ethics, but I do not follow him when he tends to deny that there are such distinctions and that these can be characterized. He does not succeed in showing why moral philosophy has no particular subject matter, why Wittgenstein would be wrong in claiming that this subject matter is (roughly) "what is good" and why there can be no such thing as meta-ethics.

\section{4. "A ClassificAtion By USE RATHER Than By SUbJeCt MATteR"}

Our authors all emphasize that what makes a statement moral is not its subject matter but its use. Diamond writes that "being about good and evil is a matter of use, not subject matter" $(1996,244)$, that the moral character of a sentence "arises not through its content but from its use on particular occasions" $(1996,248)$ and that "what makes a statement moral [... is not its subject matter [...] but its use" (1996, 253). Mulhall approvingly mentions Diamond's finding that "what makes a stretch of discourse [...] moral [...] is a matter of use, not properties denoted or subject-matter" $(2002,306)$ and Richter does just the same $(1996,253)$. They suggest that, if what makes a statement moral is not its subject matter but its use, it may be doubted whether ethics has a subject matter at all.

Diamond writes:

We have seen Wittgenstein's view that a particular sentence might belong to pomology or might belong to mathematics, and which it belongs to depends not on what it is apparently about but on its use. Why not consider the question, then, whether a sentence's belonging to ethics is a classification by use rather than by subject matter? $(1996,237)$ 
[This is an Accepted Manuscript of an article published in Ethical Perspectives 22/1 (2015), 6998. The final publication is available via http://www.ethical-

perspectives.be/page.php?FILE=ep_detail\&ID=205\&TID=1849. Please cite the published version only.]

The particular sentence Diamond refers to is the sentence " 20 apples plus 30 apples is 50 apples", of which Wittgenstein says in his Lectures on the Foundations of Mathematics that it may be about apples as well as about numbers, depending on its use (Diamond 1989, 113). Which category a sentence belongs to depends, as Diamond writes, "not on what it is apparently about but on its use". The word "apparently" is of crucial importance here: a sentence may appear to be about something, but when we have a closer look at how it is used, it may turn out that we have been misled by the surface grammar of the sentence and that the sentence is actually about something else. So, although which category a sentence belongs to does indeed not depend on what it is apparently about, it does depend on what it is actually about. In Diamond's example, as in many other examples, we cannot decide on what the sentence is about or on what its subject matter is without looking at how the sentence is used. What the example shows is that subject matter is determined by use. A classification of the sentence " 20 apples plus 30 apples is 50 apples" as a pomological rather than a mathematical sentence is a classification by subject matter, and because such a classification crucially depends on the use of the sentence, it can at the same time rightfully be conceived as a classification by use. Because a classification by use can at the same time be a classification by subject matter, showing that something is a classification by use does not amount to showing that it is not a classification by subject matter. When Diamond asks "whether a sentence's belonging to ethics is a classification by use rather than by subject matter?" (1996, 237), she suggests that there is a conflict or opposition between use and subject matter, while "use or subject matter?" is, in the light of Wittgenstein's famous "meaning is use" $(2009, \S 43)$, a false dilemma. ${ }^{7}$

I do not want to suggest that there is no distinction to make between classifications by use and classifications by subject matter, I only want to stress that there is no conflict, that the two types of classification are not mutually exclusive. As Diamond rightly points out, a classification of sentences as "proverbs" is a classification by use and not by subject matter, while a classification as "botanical" is a classification by subject matter. What our authors do not take sufficiently into account, however, is that the latter is also a classification by use. Being a classification by use does not exclude being a classification by subject matter, although certain classifications by use ("proverb") are not classifications by subject matter. Hence, even if the classification of sentences as "ethical" is a classification by use (which is plausible), this has no direct consequences for the question of whether ethics has a subject matter, because there is no opposition between use and subject matter. Unfortunately, our authors either need such a conflict (and I take the quotations at the beginning of this section to suggest such a conflict) if they want to argue from the fact that "ethical" is a classification by use to the conclusion that ethics has no particular subject matter. 
[This is an Accepted Manuscript of an article published in Ethical Perspectives 22/1 (2015), 6998. The final publication is available via http://www.ethical-

perspectives.be/page.php?FILE=ep_detail\&ID=205\&TID=1849. Please cite the published version only.]

There is a further problem with the proposal to conceive of "ethical" as a categorization by use and not by subject matter. If ethical sentences are not ethical in virtue of their subject matter, but in virtue of their use, then one avoids questions about how to demarcate or characterize an ethical subject matter, but one immediately invites analogous questions about moral use: what is "moral use"? How can it be demarcated or characterized? What kinds of uses of words and sentences are there and how is a moral use different from and similar to other kinds of uses? One could say: "These questions need not be answered, because no further characterization, specification or demarcation of 'the moral use' is possible or even desirable. Moreover, there is not just one 'moral use', but there are many ways of using words and sentences in an ethical way." Although this answer might be acceptable in other contexts, it cannot be accepted here, because analogous answers to questions about subject matter have been taken to make the very idea of an ethical subject matter problematic. An important part of the motivation to attack the idea of there being a subject matter and to claim that there can be no meta-ethics was the impossibility of compiling a closed list of distinctively moral concepts, to demarcate a particular subject matter or separable branch, to make (sharp) distinctions. May one not ask, then, how a moral use can be (sharply) distinguished or demarcated? Why would an indefinite variety of uses be more desirable than an overwhelmingly varied or complicated moral arena? "Use" seems to invite exactly the same problems as "subject matter". The only significant difference is that philosophers have spent a lot of effort in trying to characterize the subject matter of ethics, and that we have acceptable demarcations and characterizations of the subject matter of moral philosophy (such as Moore's/Wittgenstein's that the subject matter of ethics is what is good), while demarcations or characterizations of the moral use(s) (as opposed to subject matter) are scarce. The only satisfying characterizations of "moral use" one can give, I think, are those referring to a subject matter: a sentence or word is used in a moral way if it refers to what is good, or to what is absolutely good, or to what is intrinsically valuable, etc. This is the way in which I have understood "moral use" when I said that a moral vocabulary would contain only words in their moral uses. Again, it is not wrong or misleading to talk about "moral uses", but it is misleading to make it seem as if there were a conflict between use and subject matter, as if subject matter had nothing to do with use and vice versa.

Our authors' discontentment with "subject matter" goes together, as we have seen, with a fear of moral philosophy's becoming empty. If ethical sentences can be about anything, then the subject matter of moral philosophy would contain almost anything, and the idea of a moral philosophy becomes empty. My point is: if we characterize a subject matter, then ethical sentences cannot be about just anything. This, as we have shown, does not amount to setting limits to the ways in which moral thought might be expressed or fixing in advance what might count as ethical language, something to which Diamond (1996, 249), Richter (1996, 253) and Mulhall (2002, 310) rightly object. It does amount, 
[This is an Accepted Manuscript of an article published in Ethical Perspectives 22/1 (2015), 6998. The final publication is available via http://www.ethical-

perspectives.be/page.php?FILE=ep_detail\&ID=205\&TID=1849. Please cite the published version only.]

however, to setting limits to what moral thought or moral sentences can be about, to saying, for example, that they are about "what is good". Characterizing or demarcating a subject matter thus prevents moral philosophy from becoming empty rather than causing it to be so. By contrast, refusing to characterize or demarcate what a moral use is does threaten to make "moral use", and a conception of moral philosophy depending on it, empty, rather than preventing it from becoming so. Consider, in this regard, Hertzberg's saying that "moral considerations may come to be expressed in any kind of thing we say" (2002, 255).Thus, in meeting one of the main concerns of its proponents, a fear of emptiness, "use" seems to come out worse than "subject matter". Rather than saving moral philosophy, an exclusive focus on use makes it impossible. Only Richter has seen that this is where the Diamond-Mulhall-RichterHertzberg-Conant argument may lead us, and he has accepted that consequence. Unfortunately, he attributes it also to Wittgenstein:

It appears, then, that Wittgenstein was right to believe that there is no special ethical arena that could be the subject of moral philosophy or ethics. It does not follow from anything in the Investigations that moral philosophy is possible. $(1996,254)$

Richter is mistaken in attributing his conclusion to Wittgenstein. First, as we have seen, Richter takes Wittgenstein's thinking about ethics to have changed little during his career. In “A Lecture on Ethics", Wittgenstein explicitly says that ethics has a subject matter. Moreover, he speaks of "the characteristic features of ethics" $(2014,43)$. Would this not be very strange if he took ethics to be impossible? Second, even if we assume that the later Wittgenstein changed his mind, Richter has not made clear why the later Wittgenstein would have believed that there is no special ethical arena. He may be right in saying that "it does not follow from anything in the Investigations that moral philosophy is possible", but this is a strange way of putting things. Richter takes Wittgenstein to believe that moral philosophy is impossible, and one may thus expect him to point out that it does follow from something in the Investigations that moral philosophy is impossible. (Does it follow from anything in the Investigations that it is possible for me to go to China tomorrow? If not, then would one have to attribute to Wittgenstein the idea that it is impossible for me to do that?) Unfortunately, I cannot find in Richter's article a reference to something in the Investigations that would make moral philosophy impossible.

I conclude that Diamond et al. fail to make clear why a characterization of ethical sentences by use would avoid the problems they had with a characterization by subject matter. It seems only to invite more problems, especially because no convincing characterization by use of ethical sentences has been provided. That does not mean that an emphasis on use is pointless or irrelevant. By contrast, I think that Diamond et al. are right to insist that, in studying ethics, we should pay close attention to how sentences 
[This is an Accepted Manuscript of an article published in Ethical Perspectives 22/1 (2015), 6998. The final publication is available via http://www.ethical-

perspectives.be/page.php?FILE=ep_detail\&ID=205\&TID=1849. Please cite the published version only.]

are used. Why? Because only if we attend to their use can we know what they are about, what their subject matter is, and whether and why they are ethical sentences.

\section{5. "Ethics is a Pervasive Dimension of Life RAther Than a Distinguishable Region or STRAND OF IT"}

As an alternative to a characterization of the moral by subject matter, a characterization by use is problematic. Another alternative to a characterization by subject matter is to think about ethics as "a pervasive dimension of human thought and action" (Conant 2002, 87), as "a pervasive dimension of life rather than a distinguishable region or strand of it" (Mulhall 2002, 304). (Again, one may ask why Mulhall adds "distinguishable".) According to Mulhall, "there is good reason to think that, from the beginning to the end of his philosophical career, Wittgenstein conceived of ethics in precisely this way" $(2002,304)$. As we have seen, there is good reason to question Mulhall's claim here, especially because he explicitly stresses the continuity in Wittgenstein's thinking on ethics. Still, thinking of ethics as a pervasive dimension may be an interesting option for moral philosophy. Let us, therefore, have a look at where it leads us.

The ethical as a pervasive dimension is meant to be contrasted with the ethical as a region, a strand, an area or an arena, in short, with a characterization of the ethical by subject matter. However, it cannot be straightforwardly equated with a characterization by use: the pervasive moral dimension is "an ethical or spiritual aspect that is not retractable even in principle to certain kinds of words, or certain kinds of uses of words" (Mulhall 2002, 315, my italics; see also Hertzberg 2002, 255: "not a part, but an aspect"). Diamond characterizes the ethical as a "spirit, an attitude to the world and life", and this spirit "can penetrate any thought or talk" (2000, 153). According to Mulhall, it penetrates at least Wittgenstein's thought and talk: he asks us "to consider the possibility that he [Wittgenstein] took [...] every one of his philosophical remarks - to have an ethical point" $(2002,321)$. This may all be true, but what is this ethical point and why is it ethical? So far, one could as well say that, for example, the political, the aesthetical, the religious, the economical and even the epistemic are aspects rather than regions, not retractable to certain kinds of (uses) of words, attitudes to the world and life, spirits which can penetrate any thought or talk. Why not consider the possibility that Wittgenstein took every one of his philosophical remarks to have an aesthetical, a religious or a political point? I will ask of Mulhall what he asks of others: what is distinctive about the moral dimension? And why is it so pervasive in Wittgenstein's work? Mulhall and Diamond are not very clear on these matters (at least not in the articles under discussion), but the idea of a moral dimension can be found in other writings on Wittgenstein as 
[This is an Accepted Manuscript of an article published in Ethical Perspectives 22/1 (2015), 6998. The final publication is available via http://www.ethical-

perspectives.be/page.php?FILE=ep_detail\&ID=205\&TID=1849. Please cite the published version only.]

well. I will discuss two ways in which it has been worked out. First, it has been understood in terms of a reconnection with the ordinary. Second, it has been connected to our learning to think better.

In her interesting essay "A Critical Note on the New Mythology of the Ordinary", Marilena Andronico remarks that

There is nowadays a widespread tendency to emphasize the ethical tone of Wittgenstein's philosophical work and to identify it with what is taken to be the rediscovery and acceptance of "the ordinary" (2013, 14). ${ }^{8}$

Andronico traces the tendency back to Stanley Cavell, who points at the "pervasiveness of something that may express itself as a moral or religious demand in the Investigations" and adds that "the demand is not the subject of a separate study within it, call it 'Ethics"' (Cavell 1988, 40). The moral demand in the Investigations is, according to Andronico, often taken to be exemplified in Wittgenstein's controversial remark that "What we do is to bring back words from their metaphysical to their everyday use" (Wittgenstein 2009, § 116). This task, a task for philosophers, is then "reinterpreted by Cavell and his disciples as, first and foremost, a morally valuable task, connecting us with something that can be called 'our nature"' (Andronico 2013, 15). Andronico questions (rightly, I think) whether, and if so how, "the recognition of ordinary uses of certain linguistic expressions can make the recognizer a morally better person" $(2013,15)$. Even if we assume, for the sake of the argument, that it can, we are left with two problems for the "moral dimension" account of the ethical. First, if the moral dimension is characterized in terms of rediscovery and acceptance of the ordinary, its pervasiveness in Wittgenstein's work can probably be accounted for, but why would it be a pervasive dimension of life? And if it is, why should we call it "moral"? It seems to include a lot of things we ordinarily would not call "moral", and to exclude a lot of things we ordinarily do call "moral", hence to call for a radical revision of every ordinary conception of the ethical. (If the morally valuable lies in a rediscovery and acceptance of the ordinary, this might be a morally reprehensible undertaking.) Second, a characterization of the moral in terms of rediscovery and acceptance of the ordinary seems to reintroduce a subject matter: ethics is no longer about what is good, but about what is ordinary.

Another, related, interpretation of the moral dimension has been put forward by James Conant. In “On Going the Bloody Hard Way in Philosophy” (2002), he writes:

When Wittgenstein writes "Call me a truth-seeker and I will be satisfied", he specifies the character of his striving in terms of something which is for him equally a philosophical and an ethical ideal. All philosophical thinking and writing accordingly has, for Wittgenstein, its ethical aspect. Wittgenstein thought that what (and more importantly how) we think is revelatory of who we are (and how we live), 
[This is an Accepted Manuscript of an article published in Ethical Perspectives 22/1 (2015), 6998. The final publication is available via http://www.ethical-

perspectives.be/page.php?FILE=ep_detail\&ID=205\&TID=1849. Please cite the published version only.]

and that learning to think better (and, above all, to change the ways in which one thinks) is an important means to becoming a better - i.e. to becoming (what Wittgenstein calls) "a real" - "human being". So, even though Wittgenstein, in one sense, "has no ethics" (if "ethics" names a branch of philosophy with its own proprietary subject matter), in another sense, his thinking and writing - on every page of his work - takes place under the pressure of an ethical demand. $(2002,90)$

Again, we see that the "ethical aspect" is identified with a philosophical task: learning to think better, philosophizing better (philosophizing as Wittgenstein wanted us to), is an important means to becoming a better person. If this is indeed what Wittgenstein thought, and if its pervasiveness in his work can be shown, and if this is the moral dimension pervading our lives (to be sure, Conant does not claim that, he is only concerned with the ethical demand of Wittgenstein's work), there is no way of contrasting this dimension with a subject matter. If our ethical task can be reduced to the task of thinking better, then what Wittgenstein proposes is that we think of the subject matter of ethics as "what is good thinking" instead of "what is good". If it cannot be so reduced, learning to think better is only a means to becoming better human beings. The ultimate ethical task, then, is our becoming better persons, which is perfectly in line with saying that "what is good" or "what it is to be a good person" is the subject matter of ethics. Characterizing the moral dimension in this way helps to make clear what distinguishes the moral dimension from other dimensions: becoming a better person is an ethical demand and not an aesthetical one, because it is about what is good and not about what is beautiful. I do not object to the idea of a moral dimension as such, but I suspect that, however one characterizes, specifies or demarcates the moral dimension or the ethical aspect, reference to a subject matter, to what ethics is about, will be necessary. Mulhall illustrates this. He writes that "any and every Wittgensteinian philosophical exercise will place rigorous ethical demands upon its practitioners. For it will require them to acknowledge and respect the otherness of one's other" $(2002,319) .{ }^{9}$ Why not say, then, that ethics is about acknowledgement and respect for the other's otherness and that this is (part of) the subject matter of moral philosophy? Why not say that the moral dimension, rather than being a radical alternative to the idea of there being a subject matter of moral philosophy, is the subject matter of moral philosophy?

An objection to this would be: a subject matter, like an area or region, has boundaries. To say that moral philosophy has a subject matter is to invite questions like "Where are the boundaries?" and "How can it be demarcated?" It seems impossible to answer these questions. By contrast, if the ethical is a pervasive dimension, there are no boundaries, and we do not have to answer questions about boundaries and demarcation. The problem with this objection is that it poses a false dilemma: either we should be able to say where the boundaries of moral philosophy are and how its subject matter can be demarcated, or there are no boundaries and there is no demarcation. But what if there were vague or blurred boundaries? What if there were a grey zone ${ }^{10}$ The dilemma does not have to be accepted, but 
[This is an Accepted Manuscript of an article published in Ethical Perspectives 22/1 (2015), 6998. The final publication is available via http://www.ethical-

perspectives.be/page.php?FILE=ep_detail\&ID=205\&TID=1849. Please cite the published version only.]

if one accepts it, it is understandable that our authors reject its first horn. What they are left with is the second one, which easily leads to some obscure form of mysticism, in which even to say that the moral is a "dimension" or an "aspect" may be thought to set limits and to say too much. Again, Richter is the only one who follows the argument through:

Ethics, for Wittgenstein, is not a subject nor a particular sphere or aspect of life. Everything is to do with ethics because life itself, the whole world, is, so to speak, a gift from God. $(1996,251)$

Richter accepts this conclusion and takes it to be Wittgenstein's. It is not: Wittgenstein explicitly writes that "My subject [...] is ethics" $(2014,43)$. Nevertheless, Richter understands that, if no subject matter of moral philosophy is characterized, no "moral use" or "moral dimension" specified (and how else could they be specified but by reference to a subject matter?), there is no objection to saying that "everything is to do with ethics". One of the motivations for objecting to the idea of a subject matter was that it allegedly threatens to make moral philosophy empty. We should not allow our "notion of what counts as ethical" to "become capacious to the point of emptiness" (Mulhall 2002, 303). I leave it to the reader to judge whether "everything is to do with ethics" helps to take the fear of emptiness away.

\section{Wittgenstein, Meta-Ethics And the Subject Matter of Moral Philosophy}

I conclude that Wittgensteinian moral philosophy does not exclude the possibility of there being a particular subject matter of moral philosophy. There is room, within a Wittgensteinian framework, for understanding meta-ethics as it is commonly understood (unless one takes the common understanding to involve a demand for normative neutrality): as the second-order inquiry into what people are doing when thinking about and discussing what is intrinsically good, valuable, etc. That does not mean, of course, that Wittgensteinian moral philosophy is not different from traditional moral philosophy, but only that what distinguishes Wittgensteinian moral philosophy from traditional moral philosophy is not the absence of a subject matter or the impossibility of meta-ethics. What distinguishes Wittgensteinian moral philosophy (that is, what distinguishes its thinking about the subject matter of ethics from that of other moral philosophers) will depend, more than the authors I have discussed are prepared to acknowledge, on which Wittgenstein, early or late, one takes as its model. While I do not think that moral philosophy has very much to gain from Tractarian thought (which is not to say that there is nothing to gain), the Investigations, and the later Wittgenstein in general, have much more to offer. What distinguishes later Wittgensteinian moral philosophy from both the Tractatus and traditional moral philosophy is, roughly speaking, that it promises to be less one-sided. In focusing on certain aspects of 
[This is an Accepted Manuscript of an article published in Ethical Perspectives 22/1 (2015), 6998. The final publication is available via http://www.ethical-

perspectives.be/page.php?FILE=ep_detail\&ID=205\&TID=1849. Please cite the published version only.]

its subject matter and thinking about it in certain ways, traditional moral philosophy has imprisoned itself in a small room of keywords and methods, and it has forgotten that there are alternatives, because the force of habit has made it overlook these alternatives again and again, up to the point of its not being able to see them anymore. Wittgensteinian moral philosophy reminds traditional moral philosophy of these alternatives: "The work of the philosopher consists in marshaling recollections for a particular purpose" (Wittgenstein 2009, § 127). It draws attention to them and emphasizes what has been overlooked in order for it to become visible again. The door of the room in which traditional moral philosophers have imprisoned themselves "is unlocked, opens inwards", but it has not occurred to them "to pull, rather than push against it" (Wittgenstein 1998, 47).

What are these alternatives? The value of some of the articles discussed here lies in their answers to this question (and not in their answers to questions about subject matter and meta-ethics). Hence, I am happy to refer to them for elaborated answers, and I will only point, by way of examples, at some of their general points of attention here. While traditional moral philosophy tends to focus on generalization, theory, rules, principles and judgments applicable across different contexts and circumstances in similar ways by different persons, later Wittgensteinian moral philosophy emphasizes the particularity and historicity of contexts and circumstances (forms of life and language-games). While traditional moral philosophy tends to focus on answers, Wittgensteinian moral philosophy focuses on questions and assumptions. Against moral dilemmas, the Wittgensteinian sets the creative capacity to reconceive and redescribe the situation so as to dissolve the dilemma. Against a focus on certain words and surface grammar: a focus on use. Against the search for commonalities and similarities between moral sentences and judgments: a focus on differences and the variety of the moral landscape. ${ }^{11}$ Diamond et al. have succeeded, in (what I see no objection to calling) their meta-ethical work, in showing these to be distinguishing marks of Wittgensteinian moral philosophy. None of these marks, however, makes the idea of a subject matter for moral philosophy or the possibility of meta-ethics any less plausible. ${ }^{12}$

\section{WORKS CITED}

Andronico, Marilena. 2013. "A Critical Note on the New Mythology of the Ordinary." In Mind, Language and Action. Papers of the $36^{\text {th }}$ International Wittgenstein Symposium. Edited by Danièle Moyal-Sharrock, Volker Munz and Annalisa Coliva, 14-16. Kirchberg am Wechsel: Austrian Ludwig Wittgenstein Society. Backström, Joel. 2011. "Wittgenstein and the Moral Dimension of Philosophical Problems." In The Oxford Handbook of Wittgenstein. Edited by Oskari Kuusela and Marie McGinn, 729-752. Oxford: Oxford University Press. 
[This is an Accepted Manuscript of an article published in Ethical Perspectives 22/1 (2015), 6998. The final publication is available via http://www.ethical-

perspectives.be/page.php?FILE=ep_detail\&ID=205\&TID=1849. Please cite the published version only.]

Cavell, Stanley. 1988. This New Yet Unapproachable America. Lectures after Emerson after Wittgenstein. Chicago: University of Chicago Press.

Conant, James. 2002. "On Going the Bloody Hard Way in Philosophy." In The Possibilities of Sense. Edited by John H. Whittaker, 85-129. Basingstoke: Palgrave.

De Mesel, Benjamin. 2014a. "Surveyable Representations, the 'Lecture on Ethics', and Moral Philosophy.” Nordic Wittgenstein Review 3 (2). (forthcoming)

De Mesel, Benjamin. 2014b. "Moral Modesty, Moral Judgment and Moral Advice. A Wittgensteinian Approach." International Journal of Philosophy and Theology 75 / 1: 20-37.

De Mesel, Benjamin. 2014c. "Do Moral Questions Ask for Answers?" Philosophia. Philosophical Quarterly of Israel. (forthcoming)

De Mesel, Benjamin. 2014d. "De Semantische Uniformiteit van het Morele. Over een Vooronderstelling in de Hedendaagse Metaethiek." Tijdschrift voor Filosofie 77. (forthcoming)

Diamond, Cora. (ed.) 1989. Wittgenstein's Lectures on the Foundations of Mathematics. Chicago: University of Chicago Press.

Diamond, Cora. 1996. "Wittgenstein, Mathematics, and Ethics. Resisting the Attractions of Realism." In The Cambridge Companion to Wittgenstein. Edited by Hans Sluga and David Stern, 226-260. Cambridge: Cambridge University Press.

Diamond, Cora. 2000. "Ethics, Imagination and the Method of Wittgenstein's Tractatus." In The New Wittgenstein. Edited by Alice Crary and Rupert Read, 149-173. Oxford: Routledge.

Gargani, Aldo. 2008. Wittgenstein. Musica, Parola, Gesto. Milan: Raffaello Cortina Editore.

Glock, Hans-Johann. 1996. “Abusing Use.” Dialectica 50 / 3: 205-223.

Hertzberg, Lars. 2002. "Moral Escapism and Applied Ethics." Philosophical Papers 31 / 3: 251-270.

Johnston, Paul. 1989. Wittgenstein and Moral Philosophy. London: Routledge.

Lovibond, Sabina. 1983. Realism and Imagination in Ethics. Oxford: Blackwell.

Lovibond, Sabina. 2002. Ethical Formation. Cambridge (Mass.): Harvard University Press.

Mulhall, Stephen. 2002. "Ethics in the Light of Wittgenstein." Philosophical Papers 31 / 3: 293-321.

Richter, Duncan. 1996. "Nothing to be Said. Wittgenstein and Wittgensteinian Ethics." The Southern Journal of Philosophy 34: 243-256.

Sayre-McCord, Geoffrey. 2012. "Metaethics." In The Stanford Encyclopedia of Philosophy. Edited by Edward Zalta. Spring 2012 Edition. http://plato.stanford.edu/archives/spr2012/entries/metaethics/

Schroeder, Severin. 2006. Wittgenstein. The Way Out of the Fly-Bottle. Cambridge: Polity.

Tilghman, B. R. 1987. "The Moral Dimension of the Philosophical Investigations." Philosophical Investigations 10 / 2: 99-117.

Wittgenstein, Ludwig. 1998. Culture and Value. Oxford: Blackwell.

Wittgenstein, Ludwig. 2009. Philosophical Investigations. Oxford: Wiley-Blackwell.

Wittgenstein, Ludwig. 2014. Lecture on Ethics. Oxford: Wiley-Blackwell. Edited with commentary by Edoardo Zamuner, Ermelinda Valentina Di Lascio and D. K. Levy. 
[This is an Accepted Manuscript of an article published in Ethical Perspectives 22/1 (2015), 6998. The final publication is available via http://www.ethical-

perspectives.be/page.php?FILE=ep_detail\&ID=205\&TID=1849. Please cite the published version only.]

\section{NOTES}

${ }^{1}$ I will use "ethics" and "moral philosophy", "ethical" and "moral" interchangeably. The authors I discuss, including Wittgenstein, do not make the distinction either.

${ }^{2}$ Diamond seems to acknowledge this objection as a strong objection to her argument, but she does not discuss it, because "there is no space for the kind of discussion that the objection requires" $(1996,246)$.

${ }^{3}$ Diamond explicitly recognizes this $(1996,245)$, but one can explicitly recognize an objection or problem and at the same time not answer it satisfactorily or see its full impact on one's argument.

${ }^{4}$ To say that Wittgenstein thinks that ethics has a subject matter because he writes that he will "make you see as clearly as possible what I take to be the subject matter of ethics" is to take Wittgenstein at his word here. It could be objected that this straightforward interpretation of "A Lecture on Ethics" is not the only possible one. A reviewer remarks that Wittgenstein may have done in the lecture what he did in the Tractatus: to dismiss his own propositions as sheer nonsense, not containing any intelligible doctrines. (For a defense of this interpretation of the lecture, see the introduction by Zamuner, Di Lascio and Levy to Wittgenstein 2014). I can only say here that I am not convinced by so-called Nonsense Interpretations of the Tractatus and that I take, for example, Schroeder's arguments against them $(2006,105-112)$ to be decisive. It should be clear that, if Wittgenstein did not dismiss his own propositions as sheer nonsense in the Tractatus, the proposal that he may have done something similar in the Lecture only leads to the view that he does not dismiss his own propositions as sheer nonsense in the Lecture either. In any case, if it is possible to read the lecture as calling into question its own propositions, then that is the interpretation that requires a substantial argument.

${ }^{5}$ For a discussion of this point, see De Mesel 2014a.

${ }^{6}$ The analogy of the subject matter of ethics with a country does not, of course, hold throughout. While countries do not overlap, the subject matter of ethics overlaps with the subject matter of other philosophical branches.

7 "Meaning is use" is one of the most discussed topics in the literature about Wittgenstein, so I can hardly hope to offer an uncontroversial reading here. Nevertheless, I think that my reading is relatively innocent. While some authors insist on the controversial strong view that, according to Wittgenstein, meaning is identical with use, I rely here only on the much weaker view that, according to Wittgenstein, there is no meaning without use, that meaning depends on use or is determined by use. Those who hold the strong view are also committed to the weaker one. For discussion of "meaning is use", see Glock 1996.

${ }^{8}$ The tendency is exemplified, according to Andronico, in Conant 2002, Gargani 2008 and Backström 2011.

${ }^{9}$ Tilghman provides a similar characterization of the moral dimension: "It is a continuous reminder of the language, along with the underlying form of life, that constitutes human relationships, which are, perforce, moral relationships. [...] He [Wittgenstein] has reminded us what it is to discern the humanity in a man" $(1987,116-$ 117). What I say about Mulhall's remark equally applies to Tilghman's.

${ }^{10} \mathrm{I}$ agree with Lovibond in this respect. She provides a convincing characterization of the ethical and adds that "we must resign ourselves to a state of affairs in which there will not always be a definite answer to the question whether this or that consideration is an 'ethical' (as opposed to, say, to an 'aesthetic' or an 'educational') one. But 
[This is an Accepted Manuscript of an article published in Ethical Perspectives 22/1 (2015), 6998. The final publication is available via http://www.ethical-

perspectives.be/page.php?FILE=ep_detail\&ID=205\&TID=1849. Please cite the published version only.]

though this complication may create a penumbra around the edges of the domain of ethical value, there is still a central area within which certain evaluative concepts (or in linguistic terms, predicates) will clearly fall” (2002, 33-34).

${ }^{11}$ On questions and answers in Wittgensteinian moral philosophy, see De Mesel 2014b and 2014c. Concerning the focus on differences rather than similarities between moral judgments, see De Mesel 2014d.

${ }^{12}$ I am grateful to Sabina Lovibond, Stefan Rummens and the anonymous reviewers for this journal for their comments. 